virus infection and cervical anaplasia are independently related to promiscuity, or that HSV-2 may grow preferentially in preneoplastic, or neoplastic, cervical tissue. ${ }^{3}$ Adelstein and his colleagues $^{2}$ have unfortunately no serological data to support their thesis. A. Singer ${ }^{4}$ reports that between one and four years after known infection with HSV-2 $91 \%$ of women had antibodies to the virus. Herpesviruses are persistent agents, and it might be expected therefore that the cohorts in question would have reversals in the trend of HSV-2 antibodies comparable with the mortality rates.

Attempts to isolate the virus itself from cervical lesions have been largely unsuccessful. In a study of 688 males with a history of venereal disease only 29 produced HSV-2.5 Moreover, infectious virus can rarely be found in animal cancers produced by viruses containing deoxyribonucleic acid (DNA). But there is evidence that in common with such viruses HSV-2 will "transform" hamster embryo fibroblasts in vitro" and will give a small yield of tumours after inoculation into newborn hamsters. ${ }^{7}$ Yet so do several adenovirus strains, and evidence that these play any part in human cancers (for example, respiratory system) is lacking.

A. J. Nahmias and colleagues ${ }^{7}$ have reported that HSV antigens can be detected by immunofluorescent techniques in cervical cancer cells in vivo and also in those grown in tissue culture. This is new evidence for the association of HSV-2 with carcinoma of the cervix, but the association may have no bearing on the cause of the cancer. What is needed now is for epidemiologists to study two comparable groups of women-one shown to have been exposed to a genital infection with HSV-2 and the other to differ in that respect only.

In the short term at least one line of investigation could repay research. The oncogenic animal viruses all appear to change the heredity of the cells which they convert to malignancy by adding, and incorporating, virus genetic material (DNA) into that of the normal cell. This additional DNA may be recognized biochemically in the cancer cell's nucleus and may possibly be identifiable in situ histochemically. ${ }^{8}$ Subject to two important provisos this is probably the best way of finding out whether a tumour is of viral origin. The first proviso is that the identification process is specific and that small pieces of normal DNA in the cell's nucleus do not interfere with it. (There is, for instance, recent evidence 9 that "normal" chick cell DNA may contain small pieces of avian tumour virus or virus-like DNA.) The second proviso is similar. It must be shown that only malignancy arises from this integration of viral and cellular DNA. It is possible that latent, or persistent, virus infections are also characterized by the persistence of viral genetic material in close association with the genetic material of the cell. If this proves to be the case for the herpesviruses, then, like the serological and epidemiological evidence, its significance will also be equivocal.

1 Hill, G. B., and Adelstein, A. M., Lancet, 1967, 2, 605.

2 Adelstein. A. M., Hill, G. B., and Maung, L., British fournal of Preventive and Social Medicine, 1971, 25, 186.

3 British Medical Fournal 1970, 4, 256

4 Singer, A., British Medical fournal, 1971, 1, 458.

5 Jeansson, S., and Molin, L., British Medical fournal, 1971, 3, 247.

- Duf, R., and Rapd, F., Fournal of Virology, 1971, 8, 469.

7 Nahmias. A. J., Naib. Z. M.. and Josey, W. E., in Onc.ngenesis and Herpesviruses, ed. P. M. Biggs, G. de The, and Payne, L. N. Herpesviruses, ed. P. M. Biggs, G. de Thé, and Payne, L. N.
Paris. International Agency for Research on Cancer, 1972 (In Press)

8 McDougall, J. K., Dunn, A. R., and Jones, K. W., Nature, 1972 , 236. 346.

- Varmus, H. E., Weiss, R. A., Friis, R. R., Levinson, W., and Bishop, I. M.', Proceedings of the National Academy of Sciences of the United States of America, 1972, 69, 20.

\section{Infection in Rheumatoid Disease}

The seriousness of infection in patients suffering from rheumatoid disease has been recognized since 1953, when its importance as a cause of death was stressed. ${ }^{1}$ That there might be an increased susceptibility to infection has also been suggested in an attempt to explain an apparent increased incidence of bronchiectasis, pneumonia, and possibly bronchitis in people suffering from rheumatoid arthritis. ${ }^{2}$ Similarly, these patients are thought to have an increased incidence of urinary infections and chronic pyelonephritis, but the interpretation of the findings is questionable because of the high ingestion of analgesics.

In 1958 attention was drawn to the problems of suppurative arthritis, often polyarticular, bone infection, and skin abscesses occuring in 12 patients with severe rheumatoid arthritis. ${ }^{4}$ Increase in joint pain and swelling in several joints, together with deterioration in general health, were first attributed to an exacerbation of the rheumatoid process. In two cases the correct diagnosis was made only when a swelling discharged pus and in three at necropsy. The most common infecting agent was a staphylococcus. Fever and leucocytosis did not always occur. The serious nature of these infections is clear from the fact that five of the first seven patients died, infection having not been suspected until too late for adequate treatment.

An increase in awareness of this problem has led to better diagnosis, but it is still not always recognized early. In a recent series of 17 such patients the mean duration of onset of symptoms to diagnosis was nine days, compared with four days in uncomplicated septic arthritis. In three there was a delay of two weeks. 5 Two of these three proved difficult to treat, suffering recurrences despite adequate antibiotic therapy initially. Staphylococcus aureus, often penicillin-resistant, was the most usual infecting organism, and in 9 of the 17 cases the same organism was cultured from swabs of ulcerated areas and such infections as a paronychia. The multiplicity of joints involved and the frequency of positive blood cultures indicates that septicaemia or bacteraemia from such sites is common. Great care should therefore be taken in the management of all ulcerated areas in any patient suffering from severe seropositive rheumatoid arthritis.

But infection is not confined to the skin, bones, and joints. Twelve patients with seropositive rheumatoid arthritis, six of whom were on corticosteroids, suffered a total of 24 infections. 6 These included septicaemic endocarditis and abscesses in many sites, including muscular areas such as the calf and thigh, ovary, pelvis, and perinephric region. Infection in the lung, sometimes leading to lung abscesses as well as empyema, was common, while suppurative pericarditis was also seen. These infections might or might not be associated with pyoarthroses and were often multiple. Of particular note was the fact that recurrent infections not necessarily with the same organism occurred at different sites in five patients. Death resulted from three of the 24 infections.

The frequency of infection in Felty's syndrome is well known. ${ }^{7}$ However, only one of these patients was considered to be suffering from this. Similarly the administration of corticotrophin and corticosteroids, particularly in high dosage, is known to predispose to infection. ${ }^{8}$ Yet in this last series only six patients were receiving steroids. 
In all published work it would appear to be the patient with serious rheumatoid disease which is seropositive and of moderately long duration who is particularly susceptible to infection. These patients may show little fever or leucocytosis. But deterioration in their general state, an exacerbation in only a few joints, a sudden rise in the erythrocyte sedimentation rate, and particularly the occurrence of rigors should make one suspect infection. In patients on corticosteroid therapy sudden collapse should never be attributed simply to adrenal insufficiency, or infection will be overlooked. The presence of an open sore should also be regarded with grave suspicion.

There is no known way of preventing these infections, but early suspicion and appropriate action by searching in the chest, urine, blood, joints, and so on will lead to earlier diagnosis, so that suitable antibiotic therapy and other necessary measures can be instituted.

1 Cobb, S., Anderson, F., and Baker, W., New England fournal of Medicine

1953, 249, 553.

Fournal, 1955, 2, 228.
Walker, W. C., Quarterly fournal of Medicine, 1967, 36, 239.

Kellgren, J. H., Ball, J., Fairbrother, R. W., and Barnes, K. L., British Medical fournal, 1958, 1, 1193.

Russell, A. S., and Ansell, B. M., Annals of the Rheumatic Diseases, 1972,

$31,40$.
6 Huskisson, E. C., and Dudley Hart, F., Annals of the Rheumatic Diseases, $1972,31,118$.

'Barnes, C. G., Turnbull, A. L., and Vernon-Roberts, B., Annals of the Rheumatic Diseases, $1971,30,359$.

${ }^{B}$ Mills, L. C., Boylston, B. F., Greene, J. A., and Moyer, J. H., fournal of the American Medical Association, 1957, 164, 1310.

\section{Stress and the Schizophrenias}

"Schizophrenia" is the most used and the most abused term in psychiatry today. The fact is that both as a noun and as a nosological concept it is of relatively recent origin-as recent indeed as 1911 , when it was first introduced into the literature by Eugen Bleuler. ${ }^{1}$ It should be emphasized that he then spoke of "the group of schizophrenias," indicating the diversity of the conditions he included under this umbrella term. It is no fault of his that in succeeding decades the concept has been narrowed, so that "schizophrenia" is now used in the singular as though it were a unitary disease like measles or mumps or a fracture of the middle third of the femur, each with a known aetiology, a recognized life history, and a calculable prognosis. So much has the term schizophrenia been debased that it has become meaningful only in accordance with its usage in a particular country. Nor need there be a high level of agreement between individual psychiatrists practising in the same country whose training or orientation may differ widely. Thus the term may have a meaning in the U.S.A. which is unacceptable in Great Britain, and in either or both countries it could easily be interpreted differently by alienist $A$ and psychoanalyst B. That confusion has become worse confounded is evident to anyone who has attempted to sift through a mountain of literature in order to discover a nugget of scientific gold.

A recent paper by Surgeon Captain G. G. Wallis ${ }^{2}$ comes near to being one of those rare discoveries, if for no other reason because it carries so many of the hallmarks of scientific method. The sample he studied is well defined and relatively homogeneous, the methodology precisely explained and adhered to, and the objective kept firmly in his sights. What is even more important is that the psychiatrists making the diagnoses are all Royal Navy medical officers who have a close relationship with each other, so guaranteeing a high degree of uniformity in their thinking and clinical practice. The diagnoses themselves are in line with accepted international standards.

The sample consists of 512 naval personnel, 476 men and 36 women, invalided from the Service between 1947 and 1956 with a diagnosis of a specified variety of schizophrenia. The mean age was 23.9 years. With the exception of a mere 19 all the patients were followed up until 30 June 1961 and an assessment made of their progress on six clinical and employment criteria. It was the estimation of stress as a predictor of the outcome of the schizophrenic illness that was specifically aimed at, and in all cases this was made before the assessment of the follow-up. To this end each of the patients in the sample was scored as objectively as possible for six varieties (units) of stress-that is, Service, family, marital, physical, personal, and other during the two months immediately before the estimated onset of the illness. Of the six units of stress no patient had more than three, and the more units per patient the higher was the incidence of physical and the lower that of personal stress.

What emerges clearly, and is validated by statistical analysis, is that the more stress to which the patient has been subjected the better the outcome of the mental illness as measured in the follow-up by a shorter time spent in mental hospitals and a higher capacity for work. Furthermore, stress as a predictor appeared to act independently of other pre-morbid factors. What is most important is that there were no significant differences between the individual types of stress in relation to indices of outcome. This was so, surprisingly enough, in relation to personal stress defined as "those facets of personality which makes living less easy" and which could be assumed to militate against adjustment to Service life. In this Darticular respect the results are at variance with other studies.

The inverse ratio between severe stress and favourable outcome would appear at first glance to be paradoxical. But, then, as every psychiatrist knows to his cost, "schizophrenia" is a most perverse illness.

\footnotetext{
1 Bleuler, E., Dementia Praecox or the Group of Schizophrenias, New York, International Universities Press, 1950

2 Wallis, G. G., British fournal of Psychiatry, 1972, 120, 375.
}

\section{Research on the Fetus}

Disquiet about the use of fetuses for research is not restricted to the lay public. Some members of the medical profession share it. This is evident from the report ${ }^{1}$ issued last week by an Advisory Group set up by the Health Departments two years ago. Its chairman was Sir John Peel, lately President of the Royal College of Obstetricians and Gynaecologists and this year President of the B.M.A., and its terms of reference were to consider the ethical, medical, social, and legal implications of using fetuses and fetal material for research.

In the lay, as in the medical, mind there is a clear distinction between using the tissues of a dead fetus and experimenting on a live fetus. The Advisory Group is careful 